\title{
Artificial Intelligence (AI) is helping to fight COVID - 19 but shouldn't be expected to solve the crisis on its own.
}

This paper was downloaded from TechRxiv (https://www.techrxiv.org).

\section{LICENSE}

CC BY 4.0

SUBMISSION DATE / POSTED DATE

27-07-2020 / 29-07-2020

\section{CITATION}

Aftab, Mohd (2020): Artificial Intelligence (AI) is helping to fight COVID - 19 but shouldn't be expected to solve the crisis on its own.. TechRxiv. Preprint. https://doi.org/10.36227/techrxiv.12722363.v1

$\mathrm{DOI}$

10.36227/techrxiv.12722363.v1 


\title{
Artificial Intelligence (AI) is helping to fight COVID - 19 but shouldn't be expected to solve the crisis on its own.
}

\author{
Mohd Zaki Aftab ${ }^{1}$ \\ Student, MBA Tech Mechanical \\ MPSTME, VL Mehta Road, Mumbai, India \\ Email:mohdzaki708@gmail.com
}

\begin{abstract}
Artificial Intelligence is employed by various scientists, universities, private firms to fight COVID - 19. AI has started to enter healthcare at a dramatic pace, owing to the current pandemic. Methods like CT scan to detect COVID related Pneumonia in the lungs, to search for new molecules, and to aid the epidemiologists who tracked the disease early on. New tracking methods are being utilized to contain the spread but are we depending too much? Will AI help or fight against us? Is this the wolf of data collection dressed in the lamb's fleece of a solution to the pandemic? Artificial Intelligence (AI) is helping to fight COVID - 19 but shouldn't be expected to solve the crisis on its own.
\end{abstract}

\section{INTRODUCTION}

What extent is AI helping us in the fight: AI is helping to synthesize new drugs, "British startup claims it has developed the first medication using AI" (Hielweil). The medication, which is meant to treat obsessive-compulsive disorder, took less than a year from conception to a trialready capsule. AI designed drugs are pretty straightforward, there are lots of possible molecules that might be useful in medication, but all human researchers can't test them all at once, so AI does the job by simulating those molecules. AI compares them to many different sets of parameters. Learning the most promising compounds faster than a human could.

"Exscientia's CEO, Andrew Hopkins, has argued that AI means synthesizing fewer compounds for testing and running fewer experiments in the search for a new medication. "Active Learning [a subcategory of a type of artificial intelligence called machine learning] algorithms automatically prioritize the most informative compounds for experimental synthesis and testing and enable the system to learn faster than humans alone," Hopkins told Recode in an email." (Hielweil)

Derek Lowe, a researcher at Novartis who works on drug discovery. On his pharmaceutical industry blog, Lowe explains how simply finding a potential compound doesn't guarantee that scientists understand the biochemical nature of the illness they're trying to treat — or that the drug will even work. (Lowe) 


\section{LITERATURE REVIEW}

\begin{tabular}{|c|c|}
\hline Description & Inference/Limitation \\
\hline $\begin{array}{l}\text { Projection of cases and mortality } \\
\text { This technology can track and forecast the nature of } \\
\text { the virus from the available data, social media and } \\
\text { media platforms, about the risks of the infection and } \\
\text { its likely spread. Further, it can predict the number } \\
\text { of positive cases and death in any region. AI can } \\
\text { help identify the most vulnerable regions, people } \\
\text { and countries and take measures accordingly. } \\
\text { (Haleem) }\end{array}$ & $\begin{array}{l}\text { Projection of cases and mortality is a } \\
\text { positive inference, this may be } \\
\text { subjected to AI's bias. }\end{array}$ \\
\hline $\begin{array}{l}\text { Contact tracing of individuals } \\
\text { AI can help analyze the level of infection by this } \\
\text { virus identifying the clusters and 'hot spots' and } \\
\text { can successfully do the contact tracing of the } \\
\text { individuals and also to monitor them. It can predict } \\
\text { the future course of this disease and likely } \\
\text { reappearance. (Haleem) }\end{array}$ & $\begin{array}{l}\text { AI is helping to fight COVID }-19 \\
\text { but at the cost of privacy, this data } \\
\text { can be stored by companies to target } \\
\text { specific products, or by authoritarian } \\
\text { governments store their data. } \\
\text { In case of a data breach, these } \\
\text { personal details may prove costly for } \\
\text { the individual. }\end{array}$ \\
\hline $\begin{array}{l}\text { Prevention of disease } \\
\text { With the help of real-time data analysis, AI can } \\
\text { provide updated information which is helpful in the } \\
\text { prevention of this disease. It can be used to predict } \\
\text { the probable sites of infection, the influx of the } \\
\text { virus, need for beds and healthcare professionals } \\
\text { during this crisis. AI is helpful for the future virus } \\
\text { and diseases prevention, with the help of previous } \\
\text { mentored data over data prevalent at different time. } \\
\text { It identifies traits, causes and reasons for the spread } \\
\text { of infection. In future, this will become an } \\
\text { important technology to fight against the other } \\
\text { epidemics and pandemics. It can provide a } \\
\text { preventive measure and fight against many other } \\
\text { diseases. In future, AI will play a vital role in } \\
\text { providing more predictive and preventive } \\
\text { healthcare. (Haleem) }\end{array}$ & $\begin{array}{l}\text { AI is subjected to bias, this being a } \\
\text { fairly great thing in terms of } \\
\text { analogies. }\end{array}$ \\
\hline
\end{tabular}




\section{IMPLEMENTATION OF AI}

Rizwan Malik, the lead radiologist at the Royal Bolton Hospital. In his hospital, patients often had to attend six hours or more for a specialist to seem at their x-rays. So, Malik designed a conservative test, that might help showcase the technology's potential. He identified a promising AI-based chest x-ray system called qXR from the Mumbai-based company Qure.ai. He then proposed to check the system for over six months. After four months of reviews from multiple hospital and NHS committees and forums, the proposal was finally approved.

But before the trial could initiate, COVID-19 hit the United Kingdom. Within weeks, Qure.ai retooled qXR to detect COVID-induced pneumonia, and Malik proposed a replacement trial, pushing for the technology to perform initial readings instead of just double-check human ones. Normally, the updates to both the tool and therefore the trial design would have initiated a full new approval process. But without more months to spare, the hospital greenlighted the adjusted proposal immediately. "The medical director said, 'Well, does one know what? If you think that it's adequate, crack on and have it away,", Malik recalls. "We'll accommodate all the remainder of it after the event." Many are using such technologies for the primary time under the pressure of staff shortages and overwhelming patient loads.

But there have been significant obstacles to translating that research into real-world applications. Privacy concerns make it challenging to collect enough data for training algorithms; issues related to bias and generalizability make regulators cautious to grant approvals. Even for applications that do get certified, hospitals rightly have their intensive vetting procedures and established protocols. "Physicians, like everybody else-we're all creatures of habit," says Albert Hsiao, a radiologist at UCSD Health. (Hao)

AI in detection: Bluedot's founder Kamran Khan's new artificial intelligence technology can automatically mine through news reports and online content from around the world, helping experts recognize anomalies that could lead to a potential epidemic or, worse, a pandemic. Kamran Khan in an interview explained the company's usage of AI and Natural Language Processing (NLP) to track diseases by analyzing about 100,000 articles in 65 languages. That data helps the company know when to notify its clients about the presence and spread of an infectious disease.

Startups which have provided solutions and expertise for monitoring and tracking during COVID -19 have received a total of $\$ 419.2$ million (approx.) (Statista). These startups have impactfully created a positive effect.

Ro which has received the most funding, more than a hundred million dollars, (\$176.1 million) is a direct-to-consumer healthcare technology company providing services such as online diagnosis and delivery of medication. The company has launched a free digital assessment for COVID-19. The service asks people about their symptoms and, if necessary, connects the user with a doctor for further consultation through a video call.

AI has been helping us not only in identification but also to find our answer to questions that have left us baffled, like why are some people severely affected by the disease? AI companies are collaborating to find an answer and to tweak the steps to fight against the deadly virus. Many aspects like Deep Learning, NLP, Face recognition are being employed to fight against the pandemic. To be precise, the resources are acting in our favour.

Using AI to explain why COVID - 19 hit some people harder than others: LabCorp, Ciox will use natural language processing, deep learning, to analyze handwritten doctor's notes. "We're 
going to have this rich data set of longitudinal data...up through the COVID test and...immediately after, which is very interesting because that's when they might have been put on antivirals or been on a respirator," Lance Berberian, LabCorp's executive vice president and chief information and technology officer, said. (SreeHarsha)

Ciox which stores millions of medical records annually in the US, LabCorp which has conducted 650000 COVID tests so far began pooling their data to analyze their data with the help of AI to predict the susceptibility and severity of the virus in the patients.

LabCorp's main role is to tell Ciox who was tested for COVID-19 and the result of that test. Ciox's job is to go through their provider network and pull medical records for those patients, both those created before the test and immediately after they tested positive. That information is converted into research-standard data.

Ciox started pulling the first charts this week, according to both companies. "We do expect to have a research quality registry in place in a matter of weeks, not months," Stephen N. Kahane, executive adviser for client partnerships at Ciox, said.

The companies say this may speed up the method of aggregating patient histories. Once these records are "de-identified," they're going to be put in training sets employed by deep learning models.

The approach will depend on a Ciox platform, called DataFit, that permits for big amounts of variability in medical records. the corporate applies multiple optical character recognition engines to refine the source data and fabric of tongue processing agents to index and parse the underlying medical concepts. The companies will investigate why the death rates for COVID-19 are higher among more vulnerable socioeconomic groups. "Is that because of social determinants of health or is it because of them having a higher prevalence of...high blood pressure or diabetes? Dr Kahane said. "We're going to look at a bunch of those things." These developments show a positive trend towards our fight against Coronavirus, AI certainly seems to try to better than harm, given that the info collected by Coix isn't utilised against the people or doesn't get leaked resulting in dire consequences of the corporate at the hands of federal

prosecutors. Talking of information misuse, we even have AI tracker tools which are developed by scientists Stanford to trace the expected positive patients. AI tracker tools: Stanford medicine scientist is functioning to form an early warning system, which surveys people within the US, employing a chatbot, it's utilized to test individuals with COVID like symptoms, classifying them by the realm type. After the classification, a concept is generated where may well be the subsequent epicentre of the pandemic, what percentage of patients are being expected thereby allocating resources correctly. "I hope that people see taking this survey as their civic duty and as a way to be involved in fighting COVID-19," Hofmann, chief of interventional radiology at Stanford said (Landi).

"We have visibility into Stanford's test results, including demographic and condition-specific detail; this will enable us to make better predictions from the national data collected," Leslie Haas, digital health strategy manager at Stanford Health Care said (Landi).

Seems that identification is at our fingertips, would that be? Well, researchers seem to aim to use our smartphones for coronavirus. Smartphones for Coronavirus: Apps that might hear your cough. Several teams of AI researchers are counting on the cough by the coronavirus patients, which many doctors say is kind of different from those that are because of flu. this may unlock the way for a faster diagnosis.

Tomas Teijeiro, a researcher in Switzerland, was inspired when doctors told his team that 
coronavirus patients had a distinctive dry cough. "They'd see a patient come in, they'd hear them coughing, and they'd say 'OK, it will be COVID,"' he said. (Fitch) Sceptics of such projects worry that AI screening apps supported audio clips won't be sufficiently reliable, potentially delaying treatment for sick people or sending healthy individuals to overloaded hospitals. The employment of biometric technologies to tackle the corona-virus is a component of the broader surveillance regimes of governments tracking their citizens' compliance with restrictions on movement. (Penty)

\section{RESULTS AND DISCUSSION}

Though AI is proving to be an important weapon in our fight against coronavirus, it's coming at a hidden cost.

Earlier this month, BlueDot, which also analyses flight data to predict the spread of infectious disease, predicted which cities in Asia were prone to next infections.

"The official information isn't always timely," Khan told Recode. "The difference between one case in a traveller and an outbreak depends upon your frontline health care worker recognizing that there is a particular disease. It could be the difference in preventing an outbreak from actually occurring." (Heilweil)

Though the fact which is always concerning is AI is subjected to bias, these systems aren't much immune to them. The above fact hardly is noticed as compared to the hype and the positive impact that AI has yielded, indeed mankind that if exaggerated seems on the verge of its collapse, is leaving no stone unturned in its pursuit to win over the virus. Companies, investors and government are partnering up to yield a better solution every moment, which leaves to ponder over the question of resources being allocated to fight against the pandemic, it seems that money is being splashed, to make humanity return to normal.

Some scientists caution that the flexibility of AI to predict outbreaks or identify at-risk populations hasn't been validated. Accurate testing data and large-scale contact tracing are still the gold standards for controlling outbreaks, they say.

The smartphones depending on coughing, have raised the eyebrows of several people, including many AI researchers. "You've got these quick-off-the-mark computer science projects that maybe hog the attention and resources away from something more deserving," said Emily Bender, a computational linguist at the University of Washington who studies the social impact of speech and language technologies. The voice projects are also wellintentioned, she said, but there's a risk that they are doing more harm than good within the globe.

In response to such criticisms, AI researchers say their efforts are focused on gathering data that might cause screening software and aid within the diagnosis, which they're bearing in mind the risks of false positives and negatives as they are doing so. Current tech-enabled efforts can suffer from the same limitation as previous attempts to use AI in health care: incomplete information. And, in the present crisis, unknowns abound because the virus is so new (Hernandez).

On concerns of privacy, "This is why we have to be critical right now, while these measures are being deployed and make sure these measures are necessary and proportionate so we don't get in a situation where our rights in the future are being eroded," Tom Fisher, a senior 
research officer at Privacy International, a U.K.-based nonprofit advocacy group that's tracking tech's role in the global response to COVID-19 says (Penty).

Communist governments seem to be authoritative, in China, authorities sourced data from phone carriers and called on private companies to form AI solutions to trace all citizens' travel patterns. In Europe, telecommunications operators are supplying governments with aggregated and anonymized itinerant location data to watch lockdown efforts, and a few countries are pushing ahead with voluntary apps to trace whom infected people have had contact with. Unlike China, Europe has strict privacy rules about what companies and organizations can do with people's data, but, under grave circumstances, governments can pass emergency bills to use citizens' data without their consent. So far, publicly announced tracking plans in Europe are in line with the bloc's strict privacy rules, in keeping with European data protection authorities. Still, the regulators say they shall keep a watchful eye to make sure no party oversteps the bounds.

\section{CONCLUSIONS}

The fast introduction of AI tools to fight the virus is being drained the name of the greater social good, but it raises important questions around accuracy, bias, discrimination, safety, and privacy. Fever detection, face recognition, and other styles of remote identity verification technology can collect sensitive data, which might put people in danger if not handled properly.

The bottom line: The pandemic helps to spur AI technologies and startups. But the speedy rollout of controversial identity verification tools is leaving concerns on the requirement for regulation.

\section{REFERENCES}

Fitch, Asa. Wall Street Journal

https://www.wsj.com/articles/smartphone-coronavirus-test-apps-would-listen-to-yourcough-11587055803 $\mathrm{mod}=$ searchresults\&page $=1 \&$ pos $=3$

Accessed 12 Jun. 2020

Hernandez, Daniela. Wall Street Journal

www.wsj.com/articles/coronavirus-trackers-try-out-ai-tools-as-eyes-turn-to$\underline{\text { reopening- } 11587294000 ? \mathrm{mod}=\text { searchresults \&page }=1 \& \text { pos }=4}$

Accessed 12 Jun. 2020

Hielweil, Rebecca. Vox

Www.vox.com/recode/2020/4/13/21214948/coronavirus-covid-cure-treatmentartificial-intelligence

Accessed 12 Jun. 2020

Hielweil, Rebecca. Vox

www.vox.com/2020/1/31/21117102/artificial-intelligence-drug-discovery-exscientia 
Accessed 12 Jun. 2020

Hielweil, Rebecca. Vox

www.vox.com/recode/2020/2/7/21125959/artificial-intelligence-coronavirusbenevolent-ai-treatment

Accessed 12 Jun. 2020

Hielweil, Rebecca. Vox

www.vox.com/recode/2020/1/28/21110902/artificial-intelligence-ai-coronavirus-

wuhan

Accessed 12 Jun. 2020

Landi, Heather. Fierce Healthcare

www.fiercehealthcare.com/tech/how-stanford-medicine-using-digital-health-toolsapps-to-fight-covid-outbreak

Accessed 12 Jun. 2020

Lowe, Derek. Science Translational Medicine

blogs.sciencemag.org/pipeline/archives/2020/01/31/another-ai-generated-drug

Accessed 12 Jun. 2020

Penty, Rebecca. Bloomberg Businessweek

www.magzter.com/article/Business/Bloomberg-Businessweek/AI-Gets-a-Chance-To$\underline{\text { Strut-Its-Stuff }}$

Accessed 12 Jun. 2020

Sreeharsha, Vinod. Wall Street Journal

www.wsj.com/articles/using-ai-to-help-explain-why-coronavirus-hits-some-peopleharder-than-others-11587115801? $\mathrm{mod}=$ searchresults\&page $=1 \&$ pos $=9$

Accessed 12 Jun. 2020

Haleem, Abid. Diabetes \& Metabolic Syndrome: Clinical Research \& Reviews https://doi.org/10.1016/i.dsx.2020.04.012

Accessed 12 Jun. 2020

Hao, Karen. MIT Technology Review

https://www.technologyreview.com/2020/04/23/1000410/ai-triage-covid-19patients-health-care/

Accessed 12 Jun. 2020 